\title{
Rare pulmonary diseases: a common fight
}

\author{
Sergio Harari ${ }^{1}$ and Marc Humbert ${ }^{2,3,4}$
}

\begin{abstract}
Affiliations: ${ }^{1}$ U.O. di Pneumologia e Terapia Semi-Intensiva Respiratoria, Servizio di Fisiopatologia Respiratoria ed Emodinamica Polmonare, Ospedale San Giuseppe, MultiMedica IRCCS, Milan, Italy. ${ }^{2}$ Faculté de Médecine, Université Paris-Sud, Université Paris-Saclay, Le Kremlin-Bicêtre, France. ${ }^{3}$ Service de Pneumologie, Centre de Référence de l'Hypertension Pulmonaire, Hôpital Bicêtre (Assistance Publique Hôpitaux de Paris), Le Kremlin-Bicêtre, France. ${ }^{4}$ Inserm UMR-S 999, Hôpital Marie Lannelongue, Le Plessis Robinson, France.
\end{abstract}

Correspondence: Sergio Harari, U.O. di Pneumologia e Terapia Semi-Intensiva Respiratoria, Servizio di Fisiopatologia Respiratoria ed Emodinamica Polmonare, Ospedale San Giuseppe, MultiMedica IRCCS, via San Vittore 12, 20123 Milan, Italy. E-mail: shararidhotmail.it

@ERSpublications

Rare pulmonary diseases represent a major field of respiratory medicine http://ow.ly/djOX30e6DT0

Cite this article as: Harari S, Humbert M. Rare pulmonary diseases: a common fight. Eur Respir Rev 2017; 26: 170059 [https://doi.org/10.1183/16000617.0059-2017].

This issue of the European Respiratory Review (ERR) includes selected articles from the 7th International Meeting on Pulmonary Rare Diseases and Orphan Drugs [1-8], as well as a Frontiers in Clinical Practice article addressing the rare disease pulmonary Langerhans cell histiocytosis (PLCH) [9].

Since its first edition in 2005, the International Meeting on Pulmonary Rare Diseases and Orphan Drugs has been held every 2 years, with the most recent meeting taking place in Milan (Italy) in February 2017. The conference, endorsed by the European Respiratory Society (ERS), is the only European meeting dedicated to the different types of rare parenchymal and vascular pulmonary diseases (see [10] for more information and slide presentations). The success of the congress is based on the many topics discussed (translational and clinical), which bring together scientists from different fields of expertise (pulmonary hypertension ( $\mathrm{PH})$, lymphangioleiomyomatosis (LAM), idiopathic pulmonary fibrosis (IPF), etc.) and offer them the unique opportunity to gain insight into a broad range of subjects within the area of respiratory medicine. The international scientific committee, composed of leading representatives of the medical community in Europe and the USA, suggested the topics to be included in the scientific programme. In 2017, the committee included Yochai Adir (Israel), Katerina Antoniou (Greece), Harold Collard (USA), Marc Humbert (France), Joel Moss (USA), Venerino Poletti (Italy), Ganesh Raghu (USA), Gérald Simonneau (France), Carlo Vancheri (Italy), Athol Wells (UK) and Sergio Harari (Italy, Congress Chair). As for past editions of the meeting, when selected articles were published in the ERR (for editorials, see [11-13]), the current issue of the ERR contains articles based on some presentations from the 7th meeting, to affirm the engagement of the $E R R$ in this area and more generally account for the space devoted by all ERS publications to rare diseases and orphan drugs as well as rare conditions linked to the most frequent pathologies (severe asthma, rare thoracic cancers and others), which share with rare diseases some aspects of research and methodology $[11,14]$.

Over the past 25 years, the interest in rare diseases in the international scientific community and especially in the respiratory area has grown remarkably. The flag of this paradigm shift is certainly carried by

Received: May 152017 | Accepted: May 172017

Conflict of interest: Disclosures can be found alongside this article at err.ersjournals.com

Provenance: Submitted article, peer reviewed.

Copyright CERS 2017. ERR articles are open access and distributed under the terms of the Creative Commons Attribution Non-Commercial Licence 4.0. 
TABLE 1 Numbers of clinical trials published on rare pulmonary diseases from 1990 to April 2017

1990-1999

2000-2009

2010-April 2017

Lymphangioleiomyomatosis
Idiopathic pulmonary fibrosis
Pulmonary hypertension
Sarcoidosis
Non-cystic fibrosis bronchiectasis

2

33

464

96
17

116

660

71

20

pulmonary arterial hypertension, a disease that has achieved very important milestones in translational research and in treatment modalities [15]. The data clearly demonstrate the important research movement that has accompanied rare respiratory diseases in recent years. Here are some examples: 1) from 1990 to 2010, there were only four clinical trials about LAM published on PubMed, while between January 1, 2010 and April 30, 2017, the number of papers on clinical trials increased to 17;2) 33 papers carried out on IPF trials were published in the decade 1990-2000, 60 the following decade and 116 in the last 7 years; and 3) the number of clinical trials on $\mathrm{PH}$ and non-cystic fibrosis bronchiectasis has recently increased very significantly (table 1). These amazing advances are clear evidence of the great work already accomplished and that which is still in progress.

Another very interesting advance is the implementation of the European Network of Reference Centres for Rare Lung Diseases within the framework of the 24 European Reference Networks (ERNs) approved in December 2016 by the European Commission's Board of Member States (https://ec.europa.eu/health/ern/ networks_en). ERN-LUNG is a network of healthcare providers dedicated to the care and investigation of patients suffering from rare respiratory diseases [16], which we believe can represent an important scientific support structure in the future. As a matter of fact and as already pointed out in one of our previous editorials [14], it is also important to identify uniform criteria for adoption by referral centres in the various European countries in the spirit of the "free circulation of patients within the European member states". In selected cases, it will also be crucial to establish dedicated European referral centres and networks capable of properly managing patients and therefore in a position to accumulate enough experience so as to maximise the necessary skills required in the management of particularly rare diseases [14].

In this issue of the ERR, a group of articles are published that provide an overview of important topics in pulmonary medicine. GIRERD et al. [1] propose an excellent and very useful overview of the complex issues related to genetic counselling in $\mathrm{PH}$, issues which are common to other rare lung diseases and therefore of current great interest. LAUNAY et al. [2] deal with the different expressions of PH in scleroderma and their clinical profiles. RUBBO and LUCAS [3] offer a comprehensive and thorough overview of primary ciliary dyskinesia and the related diagnostic and therapeutic aspects. TORRE et al. [4] explore the latest novelties in LAM and PLCH, both in terms of research, genetics and therapy. MiLANi et al. [5] tackle the subject of a little known but clinically relevant condition, lung involvement in amyloidosis, with regards to the possible clinical consequences for the affected patients. Torrisi et al. [6] take on the difficult task of exploring the indications and contraindications of antifibrotic therapies in IPF, a topical issue of great relevance, while Caminati et al. [7] discuss how to deal with the most advanced phases of this disease. Finally, RaGHU [8], a worldwide expert on IPF and other interstitial lung diseases, discusses the future landscapes for the treatment of IPF and analyses the most important and promising trials in the pharmacological therapy of this disease.

Moreover, also in the current issue of the ERR, LORILLON and TAZI [9] illustrate the current management of PLCH. Abdellatif Tazi is the leader of the French national reference centre for Langerhans cell histiocytosis, and this Frontiers in Clinical Practice article describes several clinical cases as well as key features of PLCH.

The ERR is once again delighted to publish important contributions coming from the prestigious 7 th International Meeting on Pulmonary Rare Diseases and Orphan Drugs, emphasising that rare diseases do represent a major field of medicine, not only for pulmonologists expert in rare pulmonary diseases, but for all respiratory physicians, as well as specialists from associated fields with whom we work on a daily basis in our clinical settings. This fully reflects the scientific spirit of the ERR and its editorial line [17].

\section{References}

1 Girerd B, Weatherald J, Montani D, et al. Heritable pulmonary hypertension: from bench to bedside. Eur Respir Rev 2017; 26: 170037. 
2 Launay D, Sobanski V, Hachulla E, et al. Pulmonary hypertension in scleroderma: different phenotypes. Eur Respir Rev 2017; 26: 170056.

3 Rubbo B, Lucas JS. Clinical care for primary ciliary dyskinesia: current challenges and future directions. Eur Respir Rev 2017; 26: 170023.

4 Torre O, Elia D, Caminati A, et al. New insights in lymphangioleiomyomatosis and pulmonary Langerhans cell histiocytosis. Eur Respir Rev 2017; 26: 170042.

$5 \quad$ Milani P, Basset M, Russo F, et al. The lung in amyloidosis. Eur Respir Rev 2017; 26: 170046.

6 Torrisi SE, Pavone M, Vancheri A, et al. When to start and when to stop antifibrotic therapies. Eur Respir Rev 2017; 26: 170053.

7 Caminati A, Cassandro R, Torre O, et al. Severe idiopathic pulmonary fibrosis: what can be done? Eur Respir Rev 2017; 26: 170047.

8 Raghu G. Pharmacotherapy for idiopathic pulmonary fibrosis: current landscape and future potential. Eur Respir Rev 2017; 26: 170071.

9 Lorillon G, Tazi A. How I manage pulmonary Langerhans cell histiocytosis. Eur Respir Rev 2017; 26: 170070.

10 7th International Meeting on Pulmonary Rare Diseases and Orphan Drugs. www.pulmonaryrarediseases.com Date last updated: August 2, 2017. Date last accessed: August 2, 2017.

11 Harari S, Cottin V, Humbert M. Global effort against rare and orphan diseases. Eur Respir Rev 2012; 21: 171-172.

12 Harari S, Humbert M, Cottin V. Future perspectives on rare pulmonary diseases and rare presentations of common disorders. Eur Respir Rev 2013; 22: 199-201.

13 Harari S, Humbert M, Blasi F, et al. Rare pulmonary diseases and orphan drugs: where do we stand and where are we going to? Eur Respir Rev 2015; 24: 375-377.

14 Harari S, Lau EM, Tamura Y, et al. Rare (pulmonary) disease day: "feeding the breath, energy for life!". Eur Respir J 2015; 45: 297-300.

15 Harari S. The revolution of pulmonary arterial hypertension. Eur Respir Rev 2016; 25: 361-363.

16 Humbert M, Wagner TO. Rare respiratory diseases are ready for primetime: from Rare Disease Day to the European Reference Networks. Eur Respir J 2017; 49: 1700085.

17 Harari S. The goal is to go further and do better: but how? Eur Respir Rev 2016; 25: 1-3. 